\title{
ADAPTNESS ASSESSMENT OF PEDESTRIAN STREET DURING CRISES LIKE COVID-19
}

\author{
Rashmi Kumari ${ }^{1 *}$ \\ ${ }^{1}$ Department of Architecture, National Institute of Technology Hamirpur, India
}

Received 24 August 2020; received in revised form 15 April 2021; accepted 10 April 2021

\begin{abstract}
:
The modern urban planning is focused towards encouraging pedestrian movement by ensuring their safety and comfort during the walk. Further, COVID-19 pandemic has abruptly obstructed our normal way of life that includes of our local as well as global transport systems. There is greater need of making the public places more pedestrian friendly with the provision of appropriate walking and cycling networks, which can tackle the social distancing issues. This paper presents a novel approach to quantitatively analyze the efficiency of present urban pedestrian streets in maintaining social distances among pedestrians. The survey research techniques, GIS tool and technique; statistical techniques; and space syntax methods are implemented and tested for evaluating present scenario of the pedestrian movement in relation to the urban layout, in the case of Main-Market Street of Hamirpur town of Himachal Pradesh, India. The regression and correlation analysis is performed between outcomes of axial and segment analysis to establish the interrelation among spatial structure and behavioral phenomena. This paper is an attempt to generate the need of rethinking the pedestrian planning process with more holistic approaches to achieve sustainable urban environment.
\end{abstract}

Keywords: $\quad$ Pedestrian space; space syntax; GIS; social distancing; street characteristics

(C) 2021 Journal of Urban and Environmental Engineering (JUEE). All rights reserved.

\footnotetext{
*Correspondence to: Dr. Rashmi Kumari. E-mail: rashmi@nith.ac.in
} 


\section{INTRODUCTION}

The accessibility for pedestrians has received increasing consideration during planning in the recent years. The impact of COVID-19 and the measures that are taken has impacted the local and the global transport systems as well. There is a need to achieve minimum physical distance of about two meters between two persons to prevent the spread of COVID-19, as per the recommendations of the world health organization. So, it is imperative to analyze the present scenario of the urban streets in view of achieving the required distance among the pedestrians; and rethinking about the planning process from the lessons learned to safeguard the future generation from the possible situations like COVID-19. It has been established through researches that the development of pedestrian responsive streets contributes towards overall sustainable development by means of economic growth, as well as social and environmental welfare (Elsawy et al., 2019; Southworth, 2005). The pedestrian accessibility has been considered to be responsible for the traffic-calming at the city level, whereas urban design has been said to intend to provide pedestrian friendly design elements at the neighborhood level. Studies suggest, Pedestrian Street is an important component of a sustainable urban system. However, most of the streets have been constructed during motorization periods, so designed considering more for motorized vehicles, and on street pedestrian spaces is typically ignored (Jain and Moraglio, 2014).

The literature suggests that the street network characteristics including degree of connectivity and level of accessibility of a street segment, is among major factors in deciding the pedestrian density at that segment (Ozbil et al., 2011). This methodology to evaluate the accessibility measures of a street network is called as the configurational approach. The configurational approach depending upon the topological attributes of the street network, are assumed to be capable of elucidating the behavioral pattern of the people in an urban system (Ozbil et. al, 2011). Studies suggest that one of the established methods based upon the configurational approach, methodology of space syntax, has been derived from topological and graphical analysis of the street network in the urban system (Hillier et al. 1993; Hillier, 1996). The topological factors, like connectivity, integration and choice, are the deciding factors for evaluating degree of accessibility of a street segment from the user perspective, in the space syntax analysis using axial maps (Hillier et al., 1993; Hillier and Iida, 2005). The number of axial lines directly crossing a line, measures the degree of connectivity of that line under investigation (Liu and Jiang, 2012). The integration level describes the average of topological distances from a definite axial line segment to each of the remaining lines in a network (Jiang, 2008). The space syntax static street network model explains the dynamism of network in a simple but robust way, and allows for a quick syntactical analysis (Kim and Penn, 2004). However, while the method can be applied to explain the spatial configurations of an urban system, the exposition of the analyses should be in concomitant with the study of socio-economic processes and behavioral pattern. The topological arrangement has considerable influence on the pedestrian movement. The pedestrian movements can be described either purely by a topological arrangement, or in consideration with other factors, like, land use pattern, road width, and socio-psychological factors (Penn et al., 1998; Jiang, 2002). The effects of land use attractiveness on pedestrian behavior are also ascertained in the recent researches. Study suggests that the land use type such as commercial, offices, recreational parks, and public transport sites has significant impact on the pedestrian density and behavior in their adjacent areas (Ozbil 2011). Several studies attempted to associate both of the land use and configurational factors. Ozer and Kubat (2007) found that pedestrian volume has maximum dependence on the sense of security from misconduct and accidents, while other important influencing factors were, results of the space syntax analysis and land use pattern (Ozer and Kubat, 2007). The correlation and regression analysis can measure interrelation between the spatial layout and the socio-economic indicators, to test sociospatial hypotheses, or to develop simulation models for evaluating socio-economic impact of spatial layout pattern (Kumari and Devadas, 2017). These predictive models may predict indicators, like rate of crime, traffic flow, number of accidents, satisfaction, ease of walk, economy generation, etc. (Klarqvist, 1993).

The major problem in the street network planning is the lack of reliable spatial as well as non-spatial data required for this purpose. The relevant, reliable, updated, easily accessible, and affordable data is rudimentary for an effective research analysis and decision making process. The demand for authentic information requires new strategies in which data regarding street network should be recognized, collected, deposited, recovered, managed, analyzed, transferred, and presented efficiently. In recent researches, Geographical Information System (GIS) has commonly been used for traffic and transportation planning, as it can be an effective tool to storage, process, and analyze the spatial and non-spatial data effectively (Das et al., 2019). GIS has the ability to access and analyze the data in view of the actual spatial location overlaid on a base map of the area under investigation. The main advantage of employing GIS is due to its capability of performing tasks, such as thematic mapping, network analysis, charting, operational with a number of layers of data and the overlay analysis, as well as owing to its friendly interface with external programs and software for data 
management and decision support (Morara and Bertolinib, 2013). There is ample opportunity to utilize tools and techniques like, GIS and space syntax for analyzing the existing pedestrian streets to assess its adaptability to achieve particular pedestrian space.

\section{Methodology}

This paper is aimed at examining the present scenario of pedestrian space in relation to the spatial characteristics in a main market street of the town. The goal is to analyze the efficiency of the street in achieving physical distancing during the walk for reducing the spread of COVID-19. The investigation focused on analyzing the existing spatial-configuration and functional attributes of the street in the Main market street of Hamirpur town. The research has been intended to examine the data regarding pedestrian behavior which has been collected using survey of selected street under investigation. The spatial features have been assessed through the topological investigation of the axial network under present study. The volume of pedestrian has been counted at all the street segments across the selected street manually using manual clicker and tally marking sheet. The measurements have been carried out in 37 different selected point at all street segments. Manual counts have been taken during the peak times, between the 2:30 pm and 7:30 pm. The survey locations have been carefully selected in order to ensure that the existing situation is observed. The axial map and attribute data were partly collected by conducting a field survey and partly by employing the Geographic Information System (GIS). The spatial configuration analysis has been done using axial map of the whole town of Hamirpur, based on space syntax analysis method. The results obtained were used as input to do correlation and regression analysis to establish the interrelation among variables (Fig. 1).

\section{About the Study Area}

The selected study area is the main market street of Hamirpur town. Hamirpur town is the Headquarter of Hamirpur district in the state of Himachal Pradesh, India. Hamirpur is located in the Himalayan range, at an average elevation of $790 \mathrm{M}$ above sea level, and its geographical co-ordinates are $31.68^{\circ} \mathrm{N}$ and $76.52^{\circ} \mathrm{E}$. Hamirpur town is spread from Jhaniari to Bhota along national highways $\mathrm{NH} 3$ and $\mathrm{NH} 103$.

There are various types of shops on the both sides of the street under present investigation, which is the major commercial street in the town in a densely populated and mixed land use area. This market area has variant characteristics due to its unplanned growth and gradual development with time according to the changing needs of the town. The street area under present investigation is highlighted and shown in the Fig. 2.

\section{Results and Discussions}

The results of present investigation shows that the space available per pedestrian various from 0.7 sqm to 17.0 sqm (Fig. 3a). Most of the main market street has less than $4.0 \mathrm{sqm}$ pedestrian space available, which is much less than required ( $4 \mathrm{sqm}$ pedestrian spaces to achieve minimum physical distance of $2 \mathrm{~m}$ ) in the situation like COVID-19. The attractiveness has been calculated by measuring the level of various selected indicators of attractiveness for a commercial street, which are: point of interest; adequacy of movement space; quality of goods and services; road condition; light facility; and nearness to parking space (Table 1). 


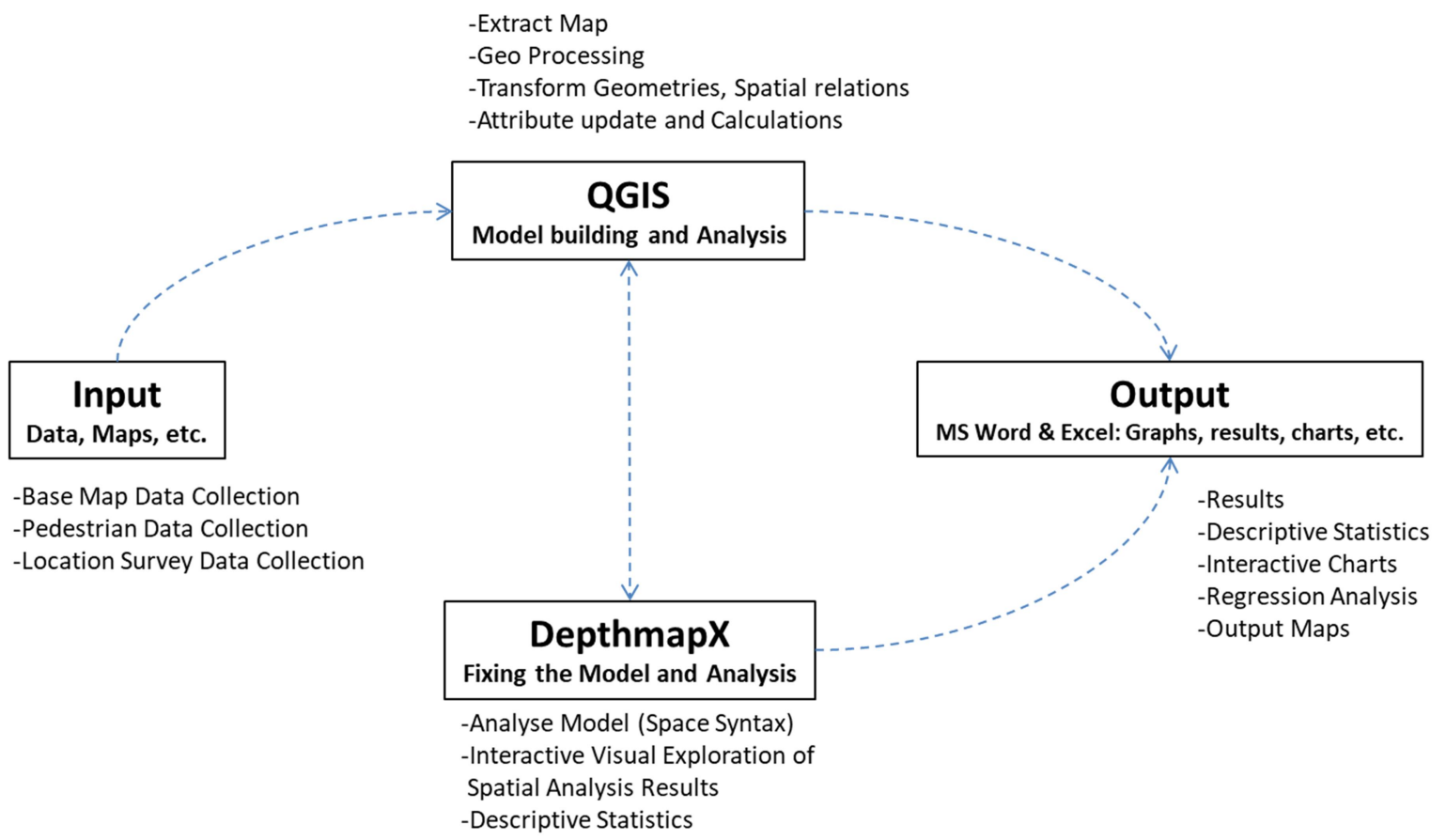

Fig. 1. Research Methodology

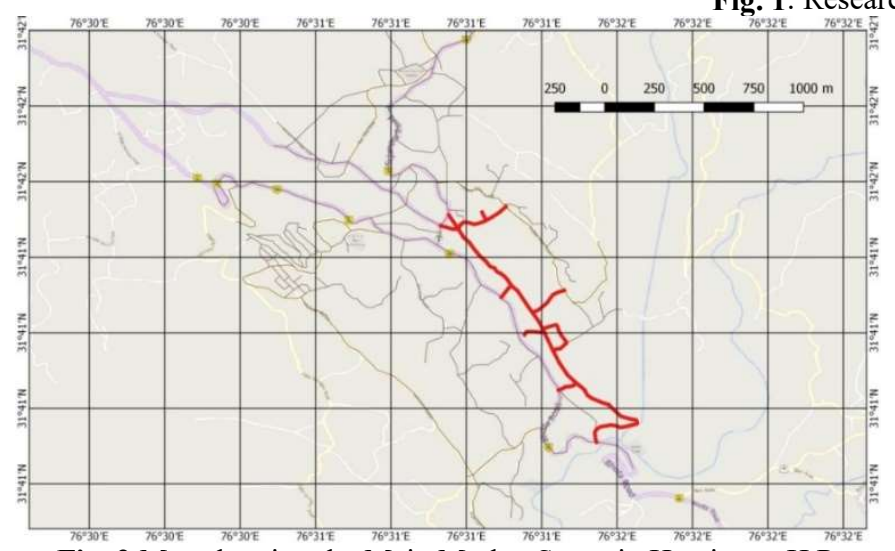

Fig. 2 Map showing the Main Market Street in Hamirpur, H.P.

The attractiveness shows higher correlation with quality of goods and services; and sense of safety (correlation coefficient $=0.8046 \& 0.8304$ respectively). However, there is a less correlation (correlation coefficient $=0.4197$ ) observed with the variable nearness to parking space (Table 1). The interrelation among structural and behavioral phenomena has been re-established. It is evident from the axial map analyzed with QGIS shown in Figs. 3b-4 that there is a strong correlation between street attractiveness and pedestrian count of the street segments (Figs. 3b-4).

(a)

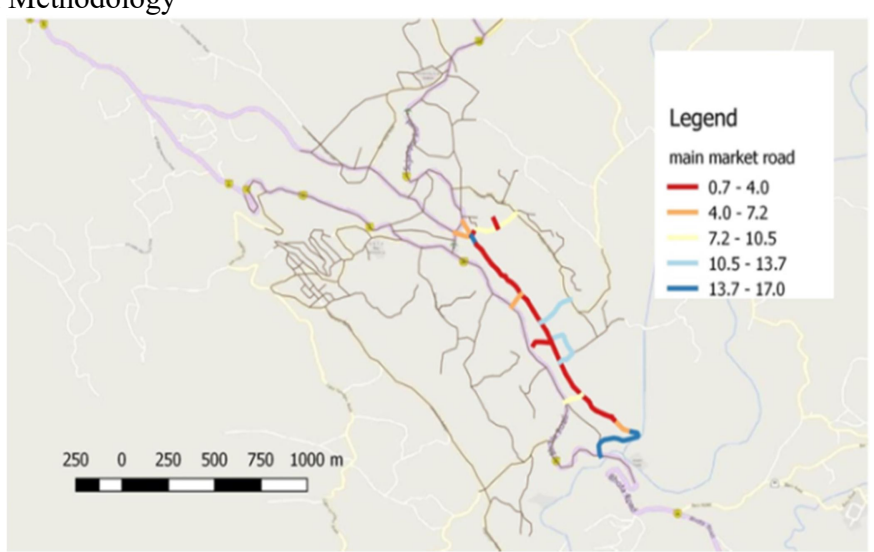

(b)

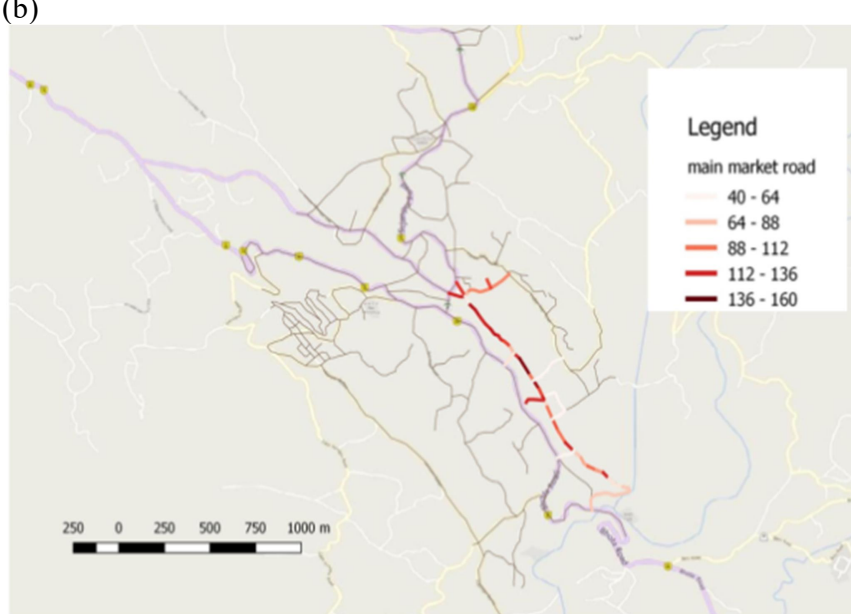

Fig. 3 (a) pedestrian space (sqm per person), and (b) pedestrian count 


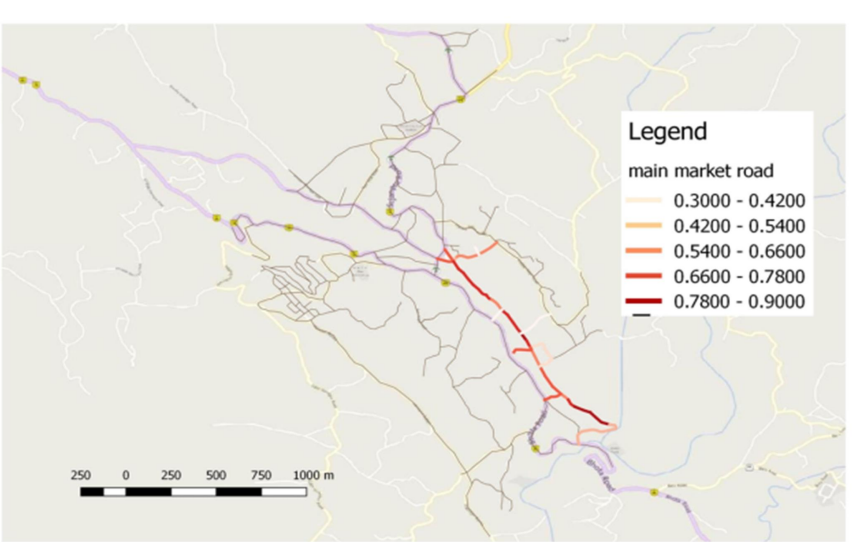

Fig. 4. Attractiveness

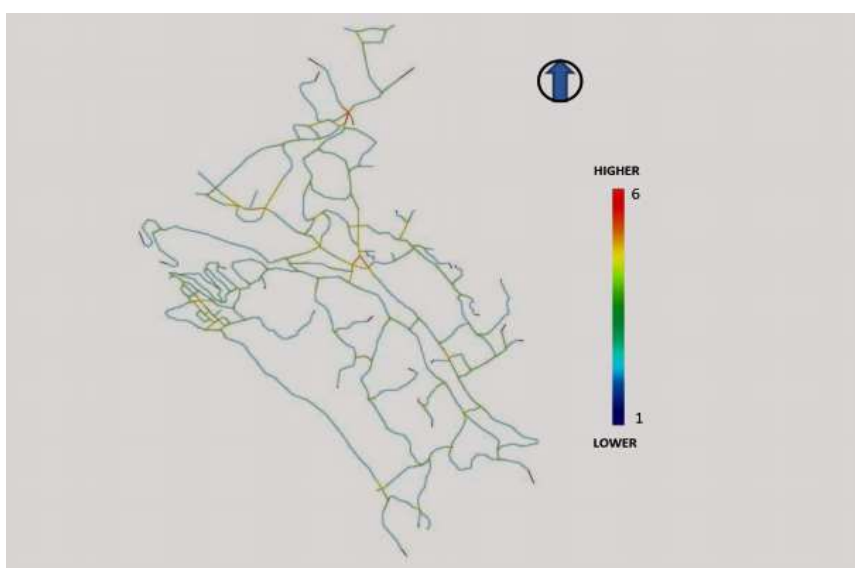

Fig. 5. Connectivity

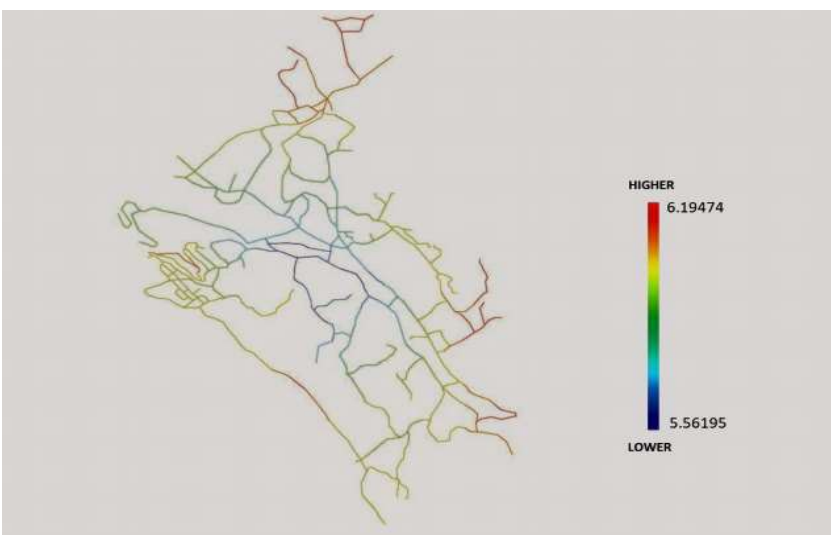

Fig. 6. Entropy

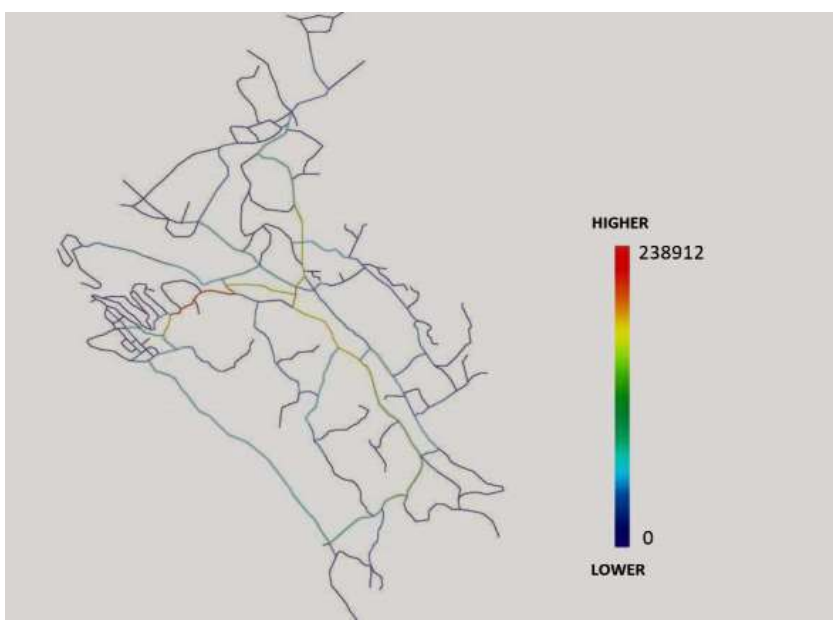

Fig. 7 Choice

Table 1. Correlation among the variables

$\begin{array}{ll}\begin{array}{l}\text { More } \\ \text { percentage }\end{array} & \begin{array}{l}\text { Adequate } \\ \text { movement }\end{array} \\ \text { of } & \text { space } \\ \text { shops/points } \\ \text { of interest }\end{array}$

$\begin{array}{ll}\text { Quality } & \text { Sense } \\ \text { of } & \text { of } \\ \text { goods } & \text { safety } \\ \text { and } & \\ \text { services } & \end{array}$

Road Nearness Attractiveness

condition to the

and light parking

facility space

of

pedestrian

during

peak

hours

\begin{tabular}{|c|c|c|c|c|c|c|c|c|}
\hline $\begin{array}{l}\text { More percentage of } \\
\text { shops/points of interest }\end{array}$ & 1 & & & & & & & \\
\hline $\begin{array}{l}\text { Adequate movement } \\
\text { space }\end{array}$ & 0.1110 & 1 & & & & & & \\
\hline $\begin{array}{l}\text { Quality of goods and } \\
\text { services }\end{array}$ & 0.8607 & 0.3133 & 1 & & & & & \\
\hline Sense of safety & 0.7530 & 0.3299 & 0.6765 & 1 & & & & \\
\hline $\begin{array}{l}\text { Road condition and } \\
\text { light facility }\end{array}$ & 0.3511 & 0.4250 & 0.3143 & 0.5609 & 1 & & & \\
\hline $\begin{array}{l}\text { Nearness to the parking } \\
\text { space }\end{array}$ & -0.1453 & 0.5821 & -0.0044 & 0.1506 & 0.3369 & 1 & & \\
\hline Attractiveness & 0.7432 & 0.6644 & 0.8046 & 0.8304 & 0.6726 & 0.4197 & 1 & \\
\hline $\begin{array}{l}\text { Avg. no. of pedestrian } \\
\text { during peak hours }\end{array}$ & 0.2794 & 0.2324 & 0.3354 & 0.5260 & 0.4860 & 0.1226 & 0.4572 & 1 \\
\hline
\end{tabular}

Table 2. Syntactic measures of the axial map

\begin{tabular}{llll}
\hline & Minimum & Average & Maximum \\
\cline { 2 - 4 } Connectivity & 1 & 2.4077 & 6 \\
\hline Mean Depth & 26.26 & 39.58 & 66.32 \\
\hline $\begin{array}{l}\text { Global } \\
\text { Integration }\end{array}$ & 0.1104 & 0.1934 & 0.2855 \\
\hline Local & 0.3333 & 1.0404 & 2.0855 \\
\hline
\end{tabular}


space more adaptable for situation like COVID-19. The minimum, average, and maximum values of connectivity, mean depth, global integration, and local integration have been observed and presented in the Table 2.

The map, showing level of connectivity of the street segments, clearly indicates that most of the axial lines on the street have moderate number (2-3) of intersecting lines; hence moderate connectivity has been observed (Fig. 5). The entropy, a measurement of the dispersal of positions of spaces in terms of their depths from a space, is almost same in the whole stretch, and the depth is more evenly distributed (Fig. 6). The map showing lower values of choice measures, which indicates that the axial lines or the street segments are less likely to be passed through on the shortest routes from all spaces to each of the remaining spaces in the entire axial network (Fig. 7). The higher values of intensity observed on the axial lines under investigation, captures that there is more movement efficiency of travelling the distances in the network (Fig. 8).

The mean depth values are less that implies that these are less number of spaces away from the original space (Fig. 9). It means number of overriding lines that needed to be crossed to reach from one space to another space is less; the least number of steps means more shallowness (integration) and less segregation. Integration values in the street under investigation have relatively higher values shows their closeness to all other spaces (Fig. 10(a)). The integration R3 has been widely accepted for investigating pedestrian movement, as it has been found that pedestrian movement in most predictable trips is averagely limited to three levels (Fig. 10b). It is evident from the maps that the pedestrian count has positive interrelations with the level of intensity and level of integration.

\section{Global Integration, Local Integration, Synergy and Intelligibility}

The axial map of local integration (radius 3 ) for the study area indicates that the most integrated axes according to global integration analysis do not always concur with the locally most integrated axes. The main market street is shows more integration in global integration analysis than local integration analysis.

The system's synergy has been assessed by the evaluation the correlation coefficient $\left(\mathrm{R}^{2}\right)$ between the local (radius 3) and global integration, which has the value 0.355 , and is represented by the corresponding equation (Fig. 11).

$y=2.6413 x+0.5297$
A high correlation coefficient means that the overall system is closer to the local system. Both measures reflect the interdependence between local and global systems.

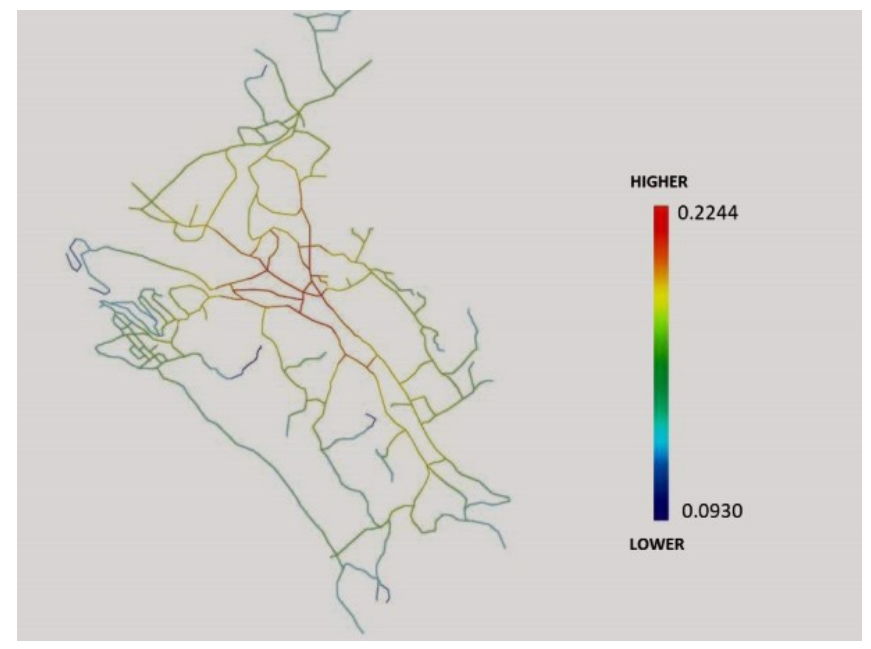

Fig. 8 Intensity

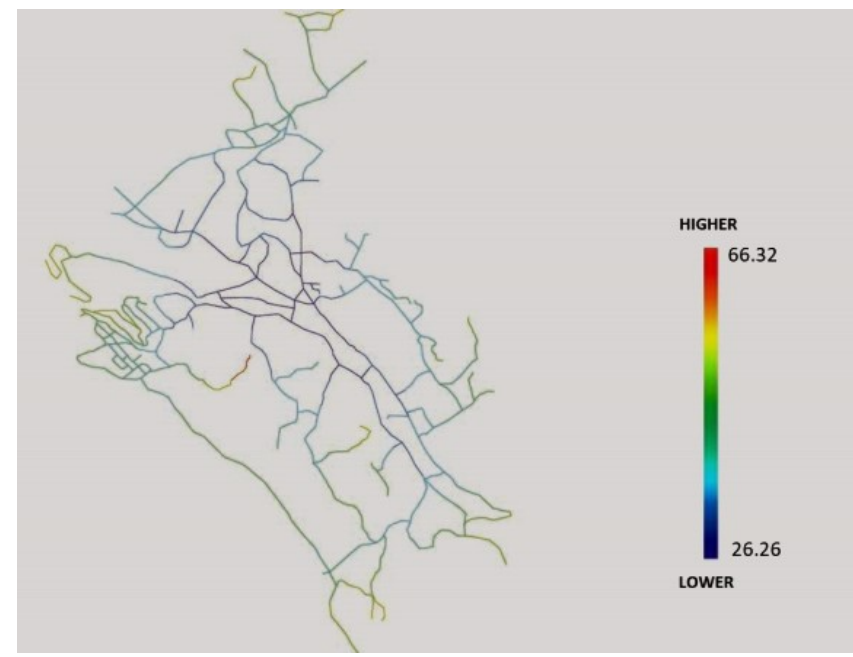

Fig. 9 Mean Depth

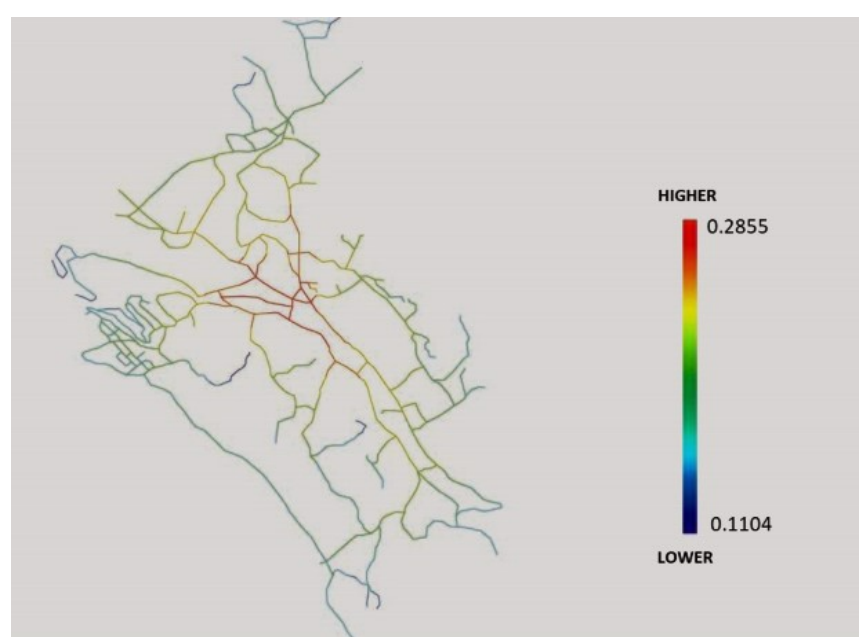

Fig. 10(a) Global Integration 


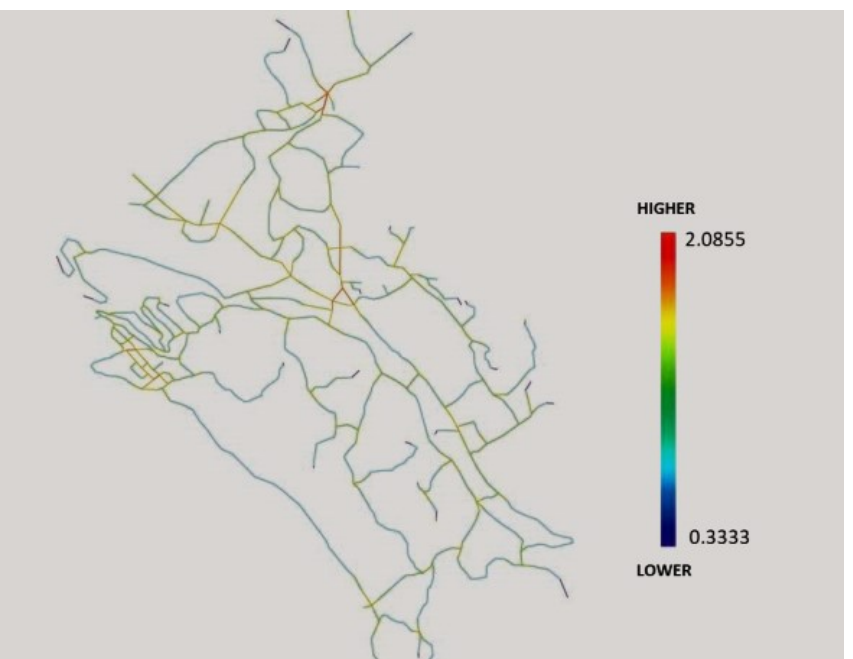

Fig. 10(b) Local Integration (R3)

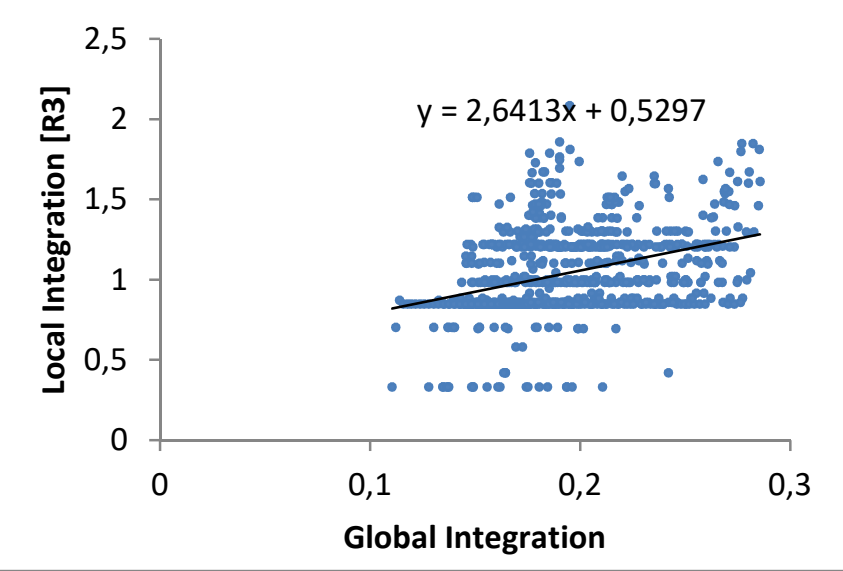

Fig. 11. Scatter plot between variables Global integration and Local Integration (R3)

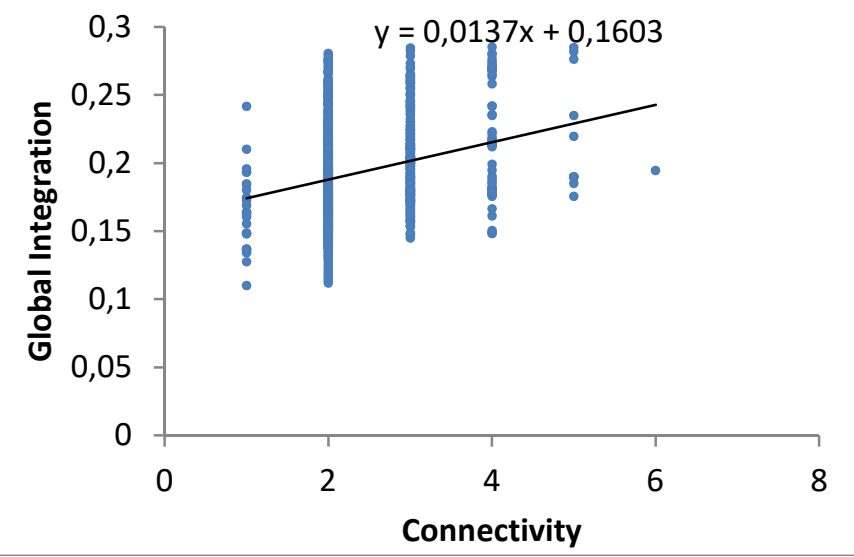

Fig. 12. Scatter plot between variables Connectivity and Global integration
The intelligibility of the urban pedestrian network is measured by the correlation coefficient $\left(\mathrm{R}^{2}\right)$ between the global integration and connectivity. The value of intelligibility in the present investigation is also average, as the value of $R^{2}$ is 0.278 , and is represented by the corresponding equation (Fig. 12).

$$
y=0.0137 x+0.1603
$$

Hence, there is moderate comfort in movement due to cognitive quality of the street's spatial configuration. The cognitive quality of the street layout at a local level does not considerably allow pedestrian to move through and to understand the overall spatial configuration of the system.

\section{Conclusion}

The present investigation focuses on the fact that essence of urban form is that it is spatially structured and functionally driven. A commercial urban street evolves as a social and spatial processing of fundamental elements: structure, intelligibility, and function. The methodology analyses the syntactical and string properties of the street to highlight their significance in assessing the safety of pedestrian during crises like covid-19, as movement behavior of pedestrian within the system of specific configuration should be respondent towards achieving the required physical distancing.

It has been found in the present investigation that people movement depends not only on the spatial syntactic variables but also on the combination of quality and types of the goods and services provided at a particular commercial segment. The study provides an analytical framework to acknowledge the degree by which the spatial and behavioral pattern of an existing street can affect the pedestrian movement. The main finding of this paper is that there exists significant correlation between pedestrian count and intelligibility, entropy, attractiveness, or connectivity. The GIS and Space Syntax methodology have been used in order to empirically analyze the spatial configurational properties of the street under investigation. The spatial and behavioral analysis of axial line predicts the pedestrian count in the present investigation. It might give some clues to urban designer as to plan and design a spatial system in order to achieve more pedestrian friendly urban areas by simulating intelligibility, Connectivity, synergy, and attractiveness to get optimum results in the dense urban areas.

The present study provides useful empirical evidence for the need of street improvements keeping in view the provisions for ease and comfort of pedestrians. On the 
other hand, the importance of this study lies on paving a way towards rethinking about the paradigm shift in the planning process of a pedestrian street keeping in view of its adaptability during crises like COVID-19.

Acknowledgment the author would like to recognize the financial support provided by the Ministry of Education, Government of India.

\section{REFERENCES}

Das, D., Ojha, A.K., Kramsapi, H. et al. (2019) Road network analysis of Guwahati city using GIS. SN Appl. Sci. 1, 906. https://doi.org/10.1007/s42452-019-0907-4

Elsawy, A. A., Ayad, H. M., Saadallah, D. (2019) Assessing livability of residential streets - Case study: El-Attarin, Alexandria, Egypt. Alexandria Engineering Journal 58(2), 745755. https://doi.org/10.1016/j.aej.2019.06.005

Hillier, B., Penn, A., Hanson, J., Grajewski, T., Xu, J. (1993) Natural movement: or configuration and attraction in urban pedestrian movement. Environment and Planning B: Planning and Design 20, 29-66.

Hillier, B. (1996) Cities as movement economies. Urban Design International 1, 49-60.

Hillier, B., \& Iida, S. (2005). Network and psychological effects in urban movement. Spatial Information Theory: International Conference, COSIT 2005, Ellicottsville.

Jain, A., Moraglio, M. (2014) Struggling for the use of urban streets: preliminary (historical) comparison between European and Indian cities. International Journal of the Commons 8(2), 513-530. DOI: http://doi.org/10.18352/ijc.461

Jiang, B., Claramunt, C. (2002) Integration of space syntax into GIS: new perspectives for urban morphology. Transactions in GIS 6 , 295-309.
Jiang B. (2008). Ranking spaces for predicting human movement in an urban environment. International Journal of Geographical Information Science. Preprint, arxiv.org/abs/physics/06-12011

Kim, Y.O., Penn, A. (2004) Linking the spatial syntax of cognitive maps to the spatial syntax of the environment. Environment and Behaviour 36(4), 483-504.

Klarqvist, B. (1993) A space syntax glossary. Nordisk Arkitekturforskning [Nordic journal of architectural research] 2 $11-12$.

Kumari, R., Devadas, V. Modelling the dynamics of economic development driven by agricultural growth in Patna Region, India. $\begin{array}{lllll}\text { Economic } & \text { Structures } & 6, & 15 & \text { (2017). }\end{array}$ https://doi.org/10.1186/s40008-017-0075-x

Liu, X., Jiang, B. (2012) Defining and generating axial lines from street center lines for better understanding of urban morphologies. International Journal of Geographical Information Science 26(8) 1521-1532. DOI: 10.1080/13658816.2011.643800

Morara, T., Bertolinib, L. (2013) Planning for Pedestrians: A Way Out of Traffic Congestion. Procedia - Social and Behavioral Sciences 81 , 600-608. https://doi.org/10.1016/j.sbspro.2013.06.483

Ozbil, A., Peponis, J., Stone, B. (2011) Understanding the link between street connectivity, land use and pedestrian flows. Urban Des Int 16, 125-141. https://doi.org/10.1057/udi.2011.2

Ozer, O., Kubat, A.S. (2007) WALKING INITIATIVES: a quantitative movement analysis. Proceedings, 6th International Space Syntax Symposium, İstanbul, 2007

Penn, A., Hillier, B., Banister, D., Xu, J. (1998) Configurational modelling of urban movement networks. Environment and Planning B: Planning and Design 25, 59-84.

Southworth, M. (2005) Designing the Walkable City. Journal of Urban Planning and Development 131(4), 246-257. DOI: 10.1061/(ASCE)0733-9488(2005)131:4(246) 